\title{
THE ROLE OF HYDROGEN PEROXIDE AND OTHER REACTIVE OXYGEN SPECIES IN WOUND HEALING
}

\begin{abstract}
Jiř́ Kanta
Charles University in Prague, Faculty of Medicine in Hradec Králové, Department of Medical Biochemistry, Czech Republic

Summary: Wound healing is a complex physiological process important for tissue homeostasis. An acute injury initiates massive cell migration, proliferation and differentiation, synthesis of extracellular matrix components, scar formation and remodelling. Blood flow and tissue oxygenation are parts of the complex regulation of healing. Higher organisms utilize molecular oxygen as a terminal oxidant. This way of gaining energy for vital processes such as healing leads to the production of a number of oxygen compounds that may have a defensive or informatory role. They may be harmful when present in high concentrations. Both the lack and the excess of reactive oxygen species may influence healing negatively.
\end{abstract}

Key words: Wound healing; Oxygen; ROS

\section{Reactive oxygen species}

Molecular oxygen is a terminal electron acceptor in organisms that gain energy by controlled oxidation of carbon compounds. The oxygen molecule $\mathrm{O}_{2}$ in its ground state (triplet oxygen) contains two unpaired electrons with parallel spin states. Four electrons are sequentially accepted by the oxygen molecule when it is reduced to water. This process gives birth to a number of intermediates and side products (18). Most of them are radicals containing an unpaired electron. Other substances (hydrogen peroxide, hypochlorous acid) are reactive but do not have a character of a radical. They are collectively called reactive oxygen species (ROS).

Superoxide anion radical is formed when the oxygen molecule accepts one electron. It can function both as a reductant and as an oxidant. Its reactivity is relatively low but it can accept a hydrogen proton and form a hydroperoxyl radical that is a stronger oxidant than $\mathrm{O}_{2}^{-}$. Hydrogen peroxide is formed in the reaction of two superoxide radicals called disproportionation. This spontaneous reaction is greatly accelerated by superoxide dismutase (SOD) (18). It is generally accepted that the reaction of superoxide radical with hydrogen peroxide in the presence of ferrous ions (the Haber-Weiss reaction) produces an extremely reactive hydroxyl radical (16). However, spectroscopic measurements indicate that the Haber-Weiss reaction produces the singlet form of molecular oxygen and not the hydroxyl radical (29). Singlet oxygen contains two electrons with antiparallel spins in contrast to the ground triplet form containing two electrons with parallel spins. It is highly reactive as it forms covalent bonds much more easily than the common triplet oxygen. Peroxynitrate is produced in the reaction of superoxide radical with nitric oxide, which is also a radical.
Peroxynitrate can be reduced by accepting a proton and then it can split to other reactive radicals (3).

When two electrons attach to the oxygen molecule, peroxide anion is produced that yields $\mathrm{H}_{2} \mathrm{O}_{2}$ by accepting two hydrogen protons. Hydrogen peroxide is also formed in the reaction of superoxide radical with hydroperoxyl radical (18). Ferrous ions $\left(\mathrm{Fe}^{2+}\right)$ reduce hydrogen peroxide; ferric ions $\left(\mathrm{Fe}^{3+}\right)$, a hydroxyl radical and a hydroxyl anion are formed in the so called Fenton reaction. $\mathrm{Fe}^{3+}$ ions are reduced back to $\mathrm{Fe}^{2+}$ by another molecule of hydrogen peroxide and a hydroperoxyl radical is formed. Hydrogen peroxide oxidizes chloride anion to hypochlorite. This reaction may be catalyzed by myeloperoxidase. Singlet oxygen is produced when hydrogen peroxide oxidizes hypochlorite (3). The reactions describing the production of various ROS are summarized in Table 1.

\section{Production and detoxification of ROS in healing wounds}

Wound healing is characterized by four distinct but overlapping phases. As blood spills into the site of injury, platelets come into contact with collagen and other extracellular matrix (ECM) components. Blood clotting factors are released and within minutes the wound is covered by a fibrin clot. Hemostasis is followed by the inflammatory phase. Neutrophils enter the wound site and remove damaged tissue and bacteria. Macrophages appear later and continue the process of phagocytosis. Both platelets and macrophages release growth factors and profibrotic cytokines such as the platelet-derived growth factor (PDGF) and the transforming growth factor beta (TGF- $\beta$ ). Mast cells release granules containing histamine and other mediators that cause surrounding vessels to become leaky and allow the passage 
of cells into the wound. In the proliferative phase endothelial cells form new capillaries. Fibroblasts migrate into the cleaned wound from the neighbouring tissue, proliferate and deposit fibronectin, collagen and other components of new ECM. Keratinocytes proliferate, migrate and restore surface integrity. Finally, during the remodeling phase, fibroblast-rich granulation tissue is gradually replaced with a relatively acellular scar. Crosslinked collagen molecules give the scar tensile strength that approximates that of the intact skin $(37,49)$.

A characteristic feature of the inflammatory phase is the oxidative burst. Polymorphonuclear cells and macrophages migrating into the wound release large amounts of superoxide radical that is converted to hydrogen peroxide by SOD. Superoxide is produced by NADPH oxidase. This enzymatic complex transfers electrons from NADPH to molecular oxygen and produces the superoxide radical. It is composed of proteins localized in phagosomal membranes and in the plasma membranes of phagocytic cells. Some components of the complex are found in the cytosol; they move to the membrane as a consequence of phagocytosis or under the influence of soluble stimulators. The activity of NADPH oxidase in phagocytes is regulated by a small GTPase Rac2 (42).

The increase in the concentration of superoxide and hydrogen peroxide is transient as the neutrophil and macrophage migration diminishes and as a result of the action of antioxidative defense systems (27). The ability of macrophages to produce ROS is much smaller than that of neutrophils but ROS and particularly $\mathrm{H}_{2} \mathrm{O}_{2}$ are important second messengers regulating physiological functions of macrophages (12). Myeloperoxidase contained in granulocytes and monocytes catalyzes the reaction of hydrogen peroxide with chloride anions; powerful oxidant hypochlorous acid is produced (42). Myeloperoxidase reaction is also a source of singlet oxygen (51).

Also nonphagocytic cells like fibroblasts contain the NADPH oxidase complex (34) or another enzymatic system generating superoxide (38). Fibroblasts secrete ROS when they are stimulated with inflammatory cytokines interleukin-1 or TNF-alpha or with growth factors EGF and PDGF (34). The level of ROS produced by nonphagocytic cells is about hundredfold less than that generated by activated phagocytes but it still may be important in signal transduction. NADPH oxidase of nonphagocytes is regulated by the protein Rac1, a member of GTPase family (16).

The lifetime and reactivity of various ROS are very different, which influences the range of their activity in the cells and the type of organelles they can affect. There are two types of defense systems that cells developed to detoxify ROS. The non-enzymatic systems comprise small antioxidant molecules, such as vitamin $C$, vitamin $\mathrm{E}, \beta$-carotene, glutathione, coenzyme $\mathrm{Q}$, bilirubin and urate. The reduced form of glutathione and ascorbate function in water solutions, the other compounds are effective in membranes and other hydrophobic media. These systems have different standard redox potentials and thus they can collaborate (40).

The enzymatic systems include three types of SOD (cytosolic, mitochondrial and extracellular), glutathione peroxidase and catalase. High levels of SOD gene expression are found at early stage of wound repair (27). Hydrogen peroxide produced by SOD can be either decomposed by catalase or used to oxidize a suitable substrate, e.g. glutathione. The expression of cytosolic and mitochondrial SOD is coordinated with the expression of catalase in the cutaneous wound (50). The oxidation of glutathione is catalyzed by glutathione peroxidase. Reduced glutathione is regenerated by the action of glutathione reductase (42).

\section{Function of ROS in healing wounds}

Majority of ROS is released by neutrophils and macrophages during the inflammatory phase of healing. Wound fluid contains micromolar concentrations of $\mathrm{H}_{2} \mathrm{O}_{2}$. ROS protect the host against bacterial and fungal infection. Partial bacteriostatic effect of $\mathrm{H}_{2} \mathrm{O}_{2}$ was observed at concentrations between $25-50 \mu \mathrm{M}$, cell killing at concentrations exceeding $500 \mu \mathrm{M}$, when the viability of E.coli was tested in vitro

Tab. 1: Important reactions in the metabolism of ROS. The arising reactive species are indicated.

\begin{tabular}{|c|c|}
\hline $\mathrm{O}_{2}+\mathrm{e}^{-} \rightarrow \mathrm{O}_{2}^{-}$ & superoxide anion radical \\
\hline $\mathrm{O}_{2}^{-} \cdot+\mathrm{H}^{+} \rightarrow \mathrm{OOH}^{\cdot}$ & hydroperoxyl radical \\
\hline $\mathrm{O}_{2}^{-} \cdot+\mathrm{O}_{2}^{-} \cdot+2 \mathrm{H}^{+} \rightarrow \mathrm{H}_{2} \mathrm{O}_{2}+\mathrm{O}_{2}$ & (disproportionation) hydrogen peroxide \\
\hline $\mathrm{O}_{2}^{-} \cdot+\mathrm{H}_{2} \mathrm{O}_{2} \rightarrow \mathrm{O}_{2}+\mathrm{OH}^{\cdot}+\mathrm{OH}^{-}$ & (Haber-Weiss reaction) hydroxyl radical \\
\hline $\mathrm{O}_{2}^{-} \cdot+\mathrm{NO} \cdot \rightarrow \mathrm{ONOO}^{-}$ & peroxynitrite \\
\hline $\mathrm{ONOO}^{-}+\mathrm{H}^{+} \rightarrow \mathrm{ONOOH} \rightarrow \mathrm{NO}_{2} \cdot+\mathrm{OH} \cdot$ & $\mathrm{NO}_{2} \cdot$ radical \\
\hline $\mathrm{O}_{2}+2 \mathrm{e}^{-} \rightarrow \mathrm{O}_{2}^{2-}$ & peroxide anion \\
\hline $\mathrm{O}_{2}^{2-}+2 \mathrm{H}^{+} \rightarrow \mathrm{H}_{2} \mathrm{O}_{2}$ & hydrogen peroxide \\
\hline $\mathrm{O}_{2}^{-} \cdot+\mathrm{OOH}^{\cdot}+\mathrm{H}^{+} \rightarrow \mathrm{H}_{2} \mathrm{O}_{2}+\mathrm{O}_{2}$ & hydrogen peroxide \\
\hline $\mathrm{H}_{2} \mathrm{O}_{2}+\mathrm{Fe}^{2+} \rightarrow \mathrm{Fe}^{3+}+\mathrm{OH} \cdot+\mathrm{OH}^{-}$ & (Fenton reaction) hydroxyl radical \\
\hline $\mathrm{H}_{2} \mathrm{O}_{2}+\mathrm{Fe}^{3+} \rightarrow \mathrm{Fe}^{2+}+\mathrm{OOH} \cdot+\mathrm{H}^{+}$ & hydroperoxyl radical \\
\hline $\mathrm{H}_{2} \mathrm{O}_{2}+\mathrm{Cl}^{-}+\mathrm{H}^{+} \rightarrow \mathrm{HClO}+\mathrm{H}_{2} \mathrm{O}$ & hypochlorous acid \\
\hline $\mathrm{H}_{2} \mathrm{O}_{2}+\mathrm{HClO} \rightarrow{ }^{1} \mathrm{O}_{2}+\mathrm{H}_{2} \mathrm{O}+\mathrm{HCl}$ & singlet oxygen \\
\hline
\end{tabular}


$(23,43)$. Hypochlorous acid with higher oxidizing potential than $\mathrm{H}_{2} \mathrm{O}_{2}$ inhibits bacterial growth by $50 \%$ at $20 \mu \mathrm{M}$ and by $100 \%$ at $50 \mu \mathrm{M}(33)$.

If the inflammatory phase does not resolve in time and the concentration of ROS exceeds the antioxidant capacity of the cell, the condition called oxidative stress results (32). Oxidative stress mediated by radical ROS (superoxide anion, hydroxyl radical) and nonradical ROS (hydrogen peroxide, singlet oxygen) may inhibit cell migration and proliferation and cause tissue damage and perpetuation of inflammation $(50,60)$. On the other hand, neutrophil defect leads to severe infections and poor wound healing. Decreased level of Rac2, the regulatory protein of phagocyte NADPH oxidase, may be a cause of this problem in patients (2).

While ROS at high concentrations have pronounced bacteriostatic effects, at low concentrations they function as second messengers. A prominent role is played by $\mathrm{H}_{2} \mathrm{O}_{2}$. It is easily synthesized, easily degraded and present within all types of cells. It has a longer half-life than radical ROS and its small uncharged molecules diffuse easily through tissues. It does not react indiscriminately with the neighbouring molecules like many radicals $(11,14)$.

Low concentrations of $\mathrm{H}_{2} \mathrm{O}_{2}(10 \mu \mathrm{M})$ act as a chemoatractant on mouse peritoneal neutrophils. This activity is not dependent on the presence of blood serum (30). $\mathrm{H}_{2} \mathrm{O}_{2}$ stimulates the proliferation of human fibroblasts and vascular endothelial cells of mammalian origin in a similar range of concentrations $(36,52)$. Overexpression of catalase in the wound can be achieved by gene transfer. The degradation of $\mathrm{H}_{2} \mathrm{O}_{2}$ by this enzyme results in the impairment of wound angiogenesis and wound closure (43). The response of cultured smooth muscle cells to PDGF, which includes chemotaxis and DNA synthesis, is blocked by catalase and by the antioxidant $\mathrm{N}$-acetylcystein and thus seems to be mediated by $\mathrm{H}_{2} \mathrm{O}_{2}$ (53).

Diminished peripheral blood flow and impaired angiogenesis and vasculogenesis are characteristic of poorely healing wounds in diabetic patients, particularly in lower extremities $(4,15)$. Low partial pressure of oxygen reduces the activity of enzymes producing ROS (19). As a consequence, the differentiation of myofibroblasts (MFB), the cells responsible for wound contraction, is impaired. The expression of $\alpha$-smooth muscle actin, the main component of myofibroblast cytoskeleton, decreases with reduced supply of oxygen, as shown in the cells transferred from $21 \%$ to $2 \%$ oxygen atmosphere. MFB lose their ability to contract matrix in vitro and possibly the wound in vivo (35). On the other hand, when human dermal fibroblasts are exposed to $2 \%$ oxygen, they produce more TGF- $\beta 1$ that mediates the increase in mRNA levels of procollagen I (10). Low oxygen tension is also a stimulus for the proliferation of human adult and neonatal dermal fibroblasts (9).

Higher concentration of $\mathrm{H}_{2} \mathrm{O}_{2}(0.5 \mathrm{mM})$ stimulates the production of macrophage inflammatory protein- $1 \alpha$ that is chemotactic for mononuclear phagocytes, neutrophils, eosinophils, basophils and lymphocytes (47). Macrophages incubated with $0.1 \mathrm{mM} \mathrm{H}_{2} \mathrm{O}_{2}$ produce vascular endothelial growth factor (VEGF) that stimulates angiogenesis. Wound angiogenesis is an important part of healing (6). However, high concentrations of $\mathrm{H}_{2} \mathrm{O}_{2}(50 \mathrm{mM})$ applied on the excisional dermal wound in mice retard wound closure (43). Sources of ROS, phenazine methosulfate applied intraperitoneally or zymosan applied topically, reduce the breaking strength of the incisions made on the back of rats (13). ROS produced by xanthine and xanthine oxidase system decrease collagen and increase glycosaminoglycan synthesis in cultured human dermal fibroblasts $(55) . \mathrm{H}_{2} \mathrm{O}_{2}$ plays a role in the activation of latent neutrophil collagenase that may degrade collagen in the wound (58). The activity of metalloproteinases in non-healing chronic ulcers is upregulated (56). $\mathrm{H}_{2} \mathrm{O}_{2}$ in concentrations 0.05 to $0.5 \mathrm{mM}$ causes apoptosis of fibroblasts (54).

Burn injury is followed by a decrease in blood flow and ischemia. Reperfusion occurs during the burn shock resuscitation, which is accompanied by an invasion of neutrophils in various tissues. Activated neutrophils produce a huge amount of ROS that cause peroxidation of membrane lipids and disruption of membranes. Damage to proteins by ROS includes oxidation of sulfhydryl groups, modification of amino groups and peptide fragmentation. Oxidative damage to DNA causes formation of adducts of base and sugar moieties as well as strand breaks $(5,41)$. Excessive release of proteases may contribute to the damage caused by neutrophils (24).

\section{Treatment of poorly healing wounds}

Hyperbaric oxygen therapy (HBOT) is a treatment in which patients breathe $100 \%$ oxygen in a pressurized chamber. At normal atmospheric pressure, the saturation of hemoglobin with oxygen is $97 \%$ and it can reach $100 \%$ in a hyperbaric chamber. The amount of oxygen dissolved in blood increases greatly when patients breathe pure oxygen at 3 ATA and large amounts of ROS are then generated (17). An improvement in wound healing and reduction in ulcer size in diabetic patients after HBOT was reported $(28,31$, $39)$. HBOT is recommended as an adjunctive therapy (7). In an experiment with human dermis in vitro, hyperbaric oxygen treatment enhanced keratinocyte migration and maturation (25). HBOT improved healing of ischemic wounds made in rats. The expression of hypoxia-inducible factor- $1 \alpha$ that plays a key role in oxygen homeostasis and subsequent downstream signalling including apoptosis was reduced (61).

Topically applied hyperbaric oxygen improved wound healing in both diabetic and non-diabetic patients. Its action was correlated with vascular endothelial growth factor (VEGF) expression (20). Topical treatment with oxygen solution in perfluorocarbon increased epithelialization of partial thickness wounds and second-degree burns made in the skin of pigs (8). Hydrogen peroxide cream containing $1.5 \% \mathrm{H}_{2} \mathrm{O}_{2}$ improved blood flow that was measured by la- 
ser Doppler technique in the wounds induced in the skin of guinea pigs (57).

In contrast to the favourable outcome of $\mathrm{O}_{2}$ or $\mathrm{H}_{2} \mathrm{O}_{2}$ treatment in patients, there are reports suggesting the need to suppress ROS formation in wounds. Antioxidant defense, reduced glutathione, ascorbic acid and vitamin E contents as well as superoxide dismutase, glutathione peroxidase and glutathione-S-transferase activities are decreased in cutaneous wounds in rats 2 to 7 days after tissue excission (48). Allopurinol or SOD solution applied on skin wounds in rats increased collagen content and breaking strength of the wounds (46). Antioxidant Trolox accelerated wound closure in diabetic rats (21). Honey has a favourable effect on wound healing because it possesses both antibacterial activity and antioxidant capacity (22).

\section{Conclusions}

Cells activated by extracellular stimuli produce ROS Cellular signalling pathways contain redox-sensitive sites and are subjected to redox regulation. Oxidants also react with nuclear transcription factors and modulate gene transcription. ROS are messengers for certain growth factors. However, oxidative stress may induce apoptosis; necrosis occurs when cells are exposed to high doses of $\operatorname{ROS}(1,26)$.

Wound oxygenation is a key factor in the healing process. Chronic ischemic wounds are often hypoxic, oxygen delivery is below tissue demand. Mild hypoxia stimulates angiogenesis and collagen formation but extreme hypoxia retards healing. Mild hypoxia supports adaptation and survival, chronic extreme hypoxia has detrimental effects $(44,45)$. Increased oxidative damage is found in Type I and Type II diabetes mellitus patients (59) or after burn injury (41). Both shortage of $\mathrm{O}_{2}$ and an excess of ROS are harmful. Efficient therapy of nonhealing wounds would require measuring the oxygenation of the tissue and maintaining it within certain limits by application of oxidants, for instance $\mathrm{H}_{2} \mathrm{O}_{2}$, or reducing agents.

\section{Acknowledgment}

This work was supported by a grant from the Ministry of Education, Youth and Sport of the Czech Republic No. MSM 0021620820.

\section{References}

1. Allen RG, Tresini M. Oxidative stress and gene regulation. Free Rad Biol Med 2000; 28:463-499.

2. Ambruso DR, Knall C, Abell AN et al. Human neutrophil deficiency syndrome is associated with an inhibitory Rac2 mutation. Proc Natl Acad Sci USA 2000; 97:4654-4659.

3. Babior BM. Phagocytes and oxidative stress. Am J Med 2000; 109:33-44

4. Brem H, Tomic-Canic M. Cellular and molecular basis of wound healing in diabetes. J Clin Invest 2007; 117:1219-1222.

5. Cetinkale O, Konukoglu D, Senel O, Kemerli GD, Yazar S. Modulating the functions of neutrophils and lipid peroxidatioon by FK506 in a rat model of thermal injury. Burns 1999; 25:105-112.

6. Cho M, Hunt TK, Hussain MZ. Hydrogen peroxide stimulates macrophage vascular endothelial growth factor release. Am J Physiol Heart Circ Physiol 2001; 280:H2357-H2363.
7. Cianci P. Advances in the treatment of the diabetic foot: Is there a role for adjunctive hyperbaric oxygen therapy? Wound Rep Reg 2004; 12:2-10.

8. Davis C, Cazzaniga AL, Ricotti $\mathrm{C}$ et al. Topical oxygen emulsion. A novel wound therapy. Arch Dermatol 2007; 143:1252-1256.

9. Falanga V, Kirsner RS. Low oxygen stimulates proliferation of fibroblasts seeded as single cells. J Cell Physiol 1993; 154:506-510.

10. Falanga V, Martin TA, Takagi $\mathrm{H}$ et al. Low-oxygen tension increases messengerRNA levels of alpha-1 (I) procollagen in human dermal fibroblasts. J Cell Physiol 1993; 157:408-412.

11. Finkel T. Oxygen radicals and signaling. Curr Opin Cell Biol 1998; 10:248-253.

12. Forman HJ, Torres M. Reactive oxygen species and cell signaling. Respiratory burst in macrophage signaling. Am J Respir Crit Care Med 2002; 166(suppl.): S4-S6.

13. Foschi D, Trabucchi E, Musazzi M et al. The effects of oxygen free radicals on wound healing. Int J Tiss Reac 1988; 10:373-379.

14. Gabbita SP, Robinson KA, Stewart CA, Floyd RA, Hensley K. Redox regulatory mechanisms of cellular signal transduction. Arch Biochem Biophys 2000; 376:1-13.

15. Gallagher KA, Liu Z-J, Xiao M et al. Diabetic impairments in NO-mediated endothelial progenitor cell mobilization and homing are reversed by hyperoxia and SDF-1 $\alpha$. J Clin Invest 2007; 117:1249-1259.

16. Gamaley IA, Klyubin IV. Roles of reactive oxygen species: signaling and regulation of cellular functions. Int Rev Cytol 1999; 188:203-255.

17. Gill AL, Bell CNA. Hyperbaric oxygen: its uses, mechanism of action and outcomes. Q J Med 2004; 97:385-395.

18. Gille G, Sigler K. Oxidative stress and living cells. Folia Microbiol 1995; 40:131152.

19. Gordillo GM, Sen CK. Revisiting the essential role of oxygen in wound healing. Am J Surg 2003; 186:259-263.

20. Gordillo GM, Roy S, Khanna S et al. Topical oxygen therapy induces vascular endothelial growth factor expression and improves closure of clinically presented chronic wounds. Clin Exp Pharmacol Physiol 2008; 35:957-964.

21. Hallberg CK, Trocme SD, Ansari NH. Acceleration of corneal wound healing in diabetic rats by the antioxidant Trolox. Res Commun Chem Pathol Pharmacol 1996; 93:3-12.

22. Henriques A, Jackson S, Cooper R, Burton N. Free radical production and quenching in honeys with wound healing potential. J Antimicrob Chemother 2006; 58:773-777.

23. Hyslop PA, Hinshaw DB, Scraufstatter IU, Cochrane GC, Kunz S, Vosbeck K. Hydrogen peroxide as a potent bacteriostatic antibiotic: implications for host defense. Free Rad Biol Med 1995; 19:31-37.

24. James TJ, Hughes MA, Cherry GW, Taylor RP. Evidence of oxidative stress in chronic venous ulcers. Wound Rep Regen 2003; 11:172-176.

25. Kairuz E, Upton Z, Dawson RA, Malda J. Hyperbaric oxygen stimulates epidermal reconstruction in human skin equivalents. Wound Rep Regen 2007; 15 266-274.

26. Kamata H, Hirata H. Redox regulation of cellular signalling. Cell Signal 1999; $11: 1-14$.

27. auf dem Keller U, Kümin A, Braun S, Werner S. Reactive oxygen species and their detoxification in healing skin wounds. J Invest Dermatol Symp Proc 2006; 11:106-111.

28. Kessler L, Bilbaut P, Ortéga F et al. Hyperbaric oxygenation accelerates the healing rate of nonischemic chronic diabetic foot ulcers. A prospective randomized study. Diabetes Care 2003; 26:2378-2382.

29. Khan AU, Kasha M. Singlet molecular oxygen in the Haber-Weiss reaction. Proc Natl Acad Sci USA 1994; 91:12365-12367.

30. Klyubin IV, Kirpichnikova KM, Gamaley IA. Hydrogen peroxide-induced chemotaxis of mouse peritoneal neutrophils. Eur J Cell Biol 1996; 70:347-351.

31. Löndahl M, Katzman P, Nilsson A, Hammarlund C. Hyperbaric oxygen therapy facilitates healing of chronic foot ulcers in patients with diabetes. Diabetes Care 2010; 33:998-1003.

32. Martindale JL, Holbrook NJ. Cellular responses to oxidative stress: signaling for suicide and survival. J Cell Physiol 2002; 192:1-15.

33. McKenna SM, Davies KJA. The inhibition of bacterial growth by hypochlorous acid. Possible role in the bactericidal activity of phagocytes. Biochem J 1988; 254:685-692.

34. Meier B, Cross AR, Hancock JT, Kaup FJ, Jones OTG. Identification of a superoxide-generating NADPH oxidase system in human fibroblasts. Biochem J 1991; 275:241-245.

35. Modarressi A, Pietramaggiori G, Godbout C, Vigato E, Pittet B, Hinz B. Hypoxia impairs skin myofibroblast differentiation and function. J Invest Dermatol 2010; 130:2818-2827.

36. Murrell GAC, Francis MJO, Bromley L Modulation of fibroblast proliferation by oxygen free radicals. Biochem J 1990; 265:659-665.

37. Nwomeh BC, Olutoye OO, Diegelmannn RF, Cohen IK. The basic biology of wound healing. J Surg Pathol 1997; 2:143-162.

38. O'Donnell VB, Azzi A. High rates of extracellular superoxide generation by cultured human fibroblasts: involvement of a lipid-metabolizing enzyme. Biochem J 1996; 318:805-812. 
39. Ong M. Hyperbaric oxygen therapy in the management of diabetic lower limb wounds. Singapore Med J 2008; 49:105-109.

40. Packer L, Valacchi G: Antioxidants and the response of skin to oxidative stress: vitamin E as a key indicator. Skin Pharmacol Appl Skin Physiol 2002; 215:282-290.

41. Parihar A, Parihar MS, Milner S, Bhat S. Oxidative stress and anti-oxidative mobilization in burn injury. Burns 2008; 34:6-17.

42. Racek J, Holeček V. Enzymy a volné radikály. Chem Listy 1999; 93:774-780.

43. Roy S, Khanna S, Nallu K, Hunt TK, Sen CK.: Dermal wound healing is subject to redox control. Mol Ther 2006; 13:211-220.

44. Sen CK, Roy S. Redox signals in wound healing. Biochim.Biophys. Acta 2008 1780:1348-1361.

45. Sen CK. Wound healing essentials: let there be oxygen. Wound Rep Reg 2009; $17: 1-18$.

46. Senel O, Cetinkale O, Özbay G, Ahcioglu F, Bulan R. Oxygen free radicals impair wound healing in ischemic rat skin. Ann Plast Surg 1997; 39:516-523.

47. Shi MM, Godleski JJ, Paulauskis JD. Regulation of macrophage inflammatory protein-1 $\alpha$ mRNA by oxidative stress. J Biol Chem 1996; 271:5878-5883.

48. Shukla A, Rasik AM, Patnaik CK. Depletion of reduced glutathione, ascorbic acid, vitamin $\mathrm{E}$ and antioxidant defence enzymes in a healing cutaneous wound. Free Rad Res 1997; 26:93-101.

49. Singer AJ, Clark RAF. Cutaneous wound healing. New England J Med 1999; 341:738-746

50. Steiling H, Munz B, Werner S, Brauchle M. Different types of ROS-scavenging enzymes are expressed during cutaneous wound repair. Exp Cell Res 1999; 247:484-494.
51. Steinbeck MJ, Khan AU, Karnovsky MJ. Intracellular singlet oxygen generation by phagocytosing neutrophils in response to particles coated with a chemical trap. J Biol Chem 1992; 267:13425-13433

52. Stone JR, Collins T. The role of hydrogen peroxide in endothelial proliferative responses. Endothelium 2002; 9:231-238.

53. Sundaresan M, Yu Z-X, Ferrans VJ, Irani K, Finkel T. Requirement for generation of $\mathrm{H}_{2} \mathrm{O}_{2}$ for platelet-derived growth factor signal transduction. Science 1995; 270:296-299.

54. Takahashi A, Aoshiba K, Nagai A. Apoptosis of wound fibroblasts induced by oxidative stress. Exp Lung Res 2002; 28:275-284.

55. Tanaka H, Okada T, Konishi H, Tsuji T. Arch Dermatol Res $1993 ; 285 \cdot 362-355$.

56. Toriseva M, Kähäri V-M. Proteinases in cutaneous wound healing. Cell Mol Life Sci 2009; 66:203-224.

57. Tur E, Bolton L, Constantine BE. Topical hydrogen peroxide treatment of ischemic ulcers in the guinea pig: blood recruitment in multiple skin sites. J Am Acad Dermatol 1995; 33:217-221.

58. Weiss SJ, Peppin G, Ortiz X, Ragsdale C, Test ST. Oxidative autoactivation of latent collagenase by human neutrophils. Science 1985; 227:747-749.

59. West IC. Radicals and oxidative stress in diabetes. Diabet Med 2000; 17: $171-180$

60. Wlaschek M, Scharffetter-Kochanek K. Oxidative stress in chronic venous leg ulcers. Wound Rep Regen 2005; 13:452-461.

61. Zhang Q, Chang Q, Cox RA, Gong X, Gould LJ. Hyperbaric oxygen attenuates apoptosis and decreases inflammation in an ischemic wound model. J Invest Dermatol 2008; 128:2102-2112.

Received: $12 / 01 / 2011$

Accepted in revised form: 18/03/2011

Dr. Jiř́ Kanta, Charles University in Prague, Faculty of Medicine in Hradec Králové, Department of Medical Biochemistry, Šimkova 870, 50038 Hradec Králové, Czech Republic; e-mail: kanta@lfhk.cuni.cz 